ARTICLE

Received 16 Nov 2016 | Accepted 7 Aug 2017 | Published 1 Sep 2017

DOl: $10.1057 /$ palcomms.2017.92

OPEN

\title{
Transformation, adaptation and development: relating concepts to practice
}

\author{
Roger Few ${ }^{1}$, Daniel Morchain ${ }^{2}$, Dian Spear ${ }^{3}$, Adelina Mensah ${ }^{4}$ and Ramkumar Bendapudi ${ }^{5}$
}

\begin{abstract}
In recent years there has been a growing number of academic reviews discussing the theme of transformation and its association with adaptation to climate change. On the one hand this has stimulated exchange of ideas and perspectives on the parameters of transformation, but it has also given rise to confusion in terms of identifying what constitutes a non-incremental form of adaptation on the ground. What this article aims to do instead is help researchers and practitioners relate different interpretations of transformation to practice by proposing a typological framework for categorising forms of change that focuses on mechanisms and objectives. It then discusses how these categorisations link to the broader conceptions and critiques noted above, with the idea that this will enable those who seek to analyse or plan adaptation to better analyse what types of action are potentially constitutive of transformation. In doing so, it should equally assist in the identification and specification of critical questions that need to be asked of such activity in relation to issues of sustainability and equity.
\end{abstract}

\footnotetext{
${ }^{1}$ School of International Development, University of East Anglia, Norwich Research Park, Norwich, UK ${ }^{2}$ Programme Strategy and Impact Team (PSIT), Oxfam GB, John Smith Drive, Oxford, UK ${ }^{3}$ African Climate and Development Initiative, University of Cape Town, Rondebosch, South Africa ${ }^{4}$ Institute for Environment and Sanitation Studies, College of Basic and Applied Sciences, University of Ghana, Accra, Ghana ${ }^{5}$ Watershed Organisation Trust, Satara road, Pune, India Correspondence: (e-mail: r.few@uea.ac.uk)
} 
$s$ the term transformation gains ground in discussions of climate change adaptation, it is necessary to take a step back, review quite what commentators mean when they use the word, and consider the implications on people, especially the most vulnerable and marginalised, of "doing" or promoting transformation in its different forms.

\section{Introduction}

The theme of transformation has been the subject of much recent discussion within academic circles and increasingly within policy arenas of environmental and climatic change. The potential to link transformation with climate change adaptation was a theme woven into the fifth assessment report of the Intergovernmental Panel on Climate Change (IPCC, 2014) and is the subject of an increasing number of international conferences. On the one hand this has led to a rich exchange of ideas and perspectives on what constitutes and promotes transformation, and what can be described as "transformational" or "transformative" adaptation. On the other hand, and almost inevitably, it has also given rise to a confusing plurality of interpretations surrounding the terms, leading to confusion in the way the ideas are being or can be applied in policy and practice (Feola, 2015; Godfrey-Wood and Naess, 2016), with the risk of the term becoming an unhelpful and potentially deleterious buzzword.

In this article, we explore, and attempt to chart an analytical course, through the various different ways the term transformation is being used in relation to climate change adaptation. Here we follow a definition of adaptation essentially as the "process of adjustment to actual or expected climate and its effects" (IPCC, 2014: 118). The focus on transformation in adaptation means that we are principally concerned with "deliberate" action, referring to interventions and processes initiated purposefully by (a range of) actors with a goal of bringing about major change (Feola, 2015; Colloff et al., 2017; Fazey et al., 2017).

A recent exercise undertaken by the authors, attempting to draw lessons about transformation and adaptation through the analysis of adaptation activities in semi-arid regions of Africa and Asia (reported in Few et al., 2016), revealed just how difficult it is to identify and classify forms of transformation when such divergent but often implicit conceptions of the term exist, especially within inter-disciplinary teams. Such differences are likely to be amplified still further when actors with different interests and visions apply the term in practice when planning or evaluating interventions. It is, frankly, unlikely that universally accepted definitions will emerge across the range of disciplines and sectors that apply the terms, but recognising this pluralism of conceptions is potentially something that contributes to an inclusive debate, facilitating a critical realignment of values and priorities in adaptation spheres.

The underlying concern of this article is how to relate conceptions of transformation to practice. As the next section indicates, this is by no means the first paper that reviews the plurality of terms and debates around transformation and adaptation (see, for example, Tanner and Bahadur, 2013; Denton et al, 2014; Feola, 2015; Fazey et al., 2017). What this article seeks to add to the literature is a framework that aims to help researchers and practitioners assess how and to what extent the mechanisms and objectives of an adaptation action are potentially constitutive of transformation.

We propose that there are three basic questions that move us toward a descriptive (typological) understanding of an adaptation activity and its connection to ideas around transformation, and, at the same time, lead us to a critical reflection of its potential to transform: what type of change process is occurring (or envisioned)?; how does it relate to the drivers of risk?; and is the change limited to climate change adaptation? After a brief review of the field in the following section, the paper uses these questions

to frame a set of typologies on "mechanisms", "target outcomes" and "the object" of change that help differentiate the multiple ways the term is used. It then reflects on how these typological distinctions interconnect with broad conceptions of transformation in the adaptation literature. The final section brings these components together and underlines the need for ongoing critical engagement.

\section{Background to terms: what's in a word?}

In essence transformation is about change-but it is not synonymous with change. For most authors, it implies change that is more than routine: a fundamental alteration of state (Tschakert et al., 2013; Feola, 2015). Conceptually, adaptation that embodies transformation, is therefore distinguished from "incremental" adaptation, in which existing practices are adjusted to make them better suited to changing conditions (Kates et al., 2012; Denton et al., 2014; Klein et al., 2014). Instead it implies something more significant-a directional shift, perhaps-but quite what passes as significant in this sense clearly remains open to interpretation.

The transformation literature is very broad, with contributions spanning the natural sciences, social sciences and humanities (O'Brien, 2012). We focus here on interpretations applied to the environmental change field, though noting that many authors working on this draw heavily on wider fields. Even within the environmental change field, there are a range of articulations of the term (Patterson et al., 2015), and a gradation from those that focus on avoiding environmental limits to those that envision a revolution in socio-political processes of development.

Probably most widely applied, and most easy to link to specific adaptation practice, is the view of transformation as "a mechanism for managing the discontinuities associated with experiencing an adaptation limit" (Klein et al., 2014: 921). Klein et al. (2014) discuss various forms of transformation, but take an underlying approach that sees transformation as a mechanism for managing situations of environmental or ecosystem change that exceed the ability of "human actors and/or natural systems" to manage through incremental adjustments. Some authors argue that approaches to adaptation that merely make adjustments to current development practices risk extending unsustainable practices in a changing environmental context in which we can no longer assume, for example, the continuation of existing patterns of seasonality, extreme events, coastal configurations, and access to water and other resources (Park et al., 2012; Dilling et al., 2015). Approaches that draw from systems ecology see transformability (the ability to undergo change) as a positive characteristic of resilient systems (Folke et al., 2010).

This process of going beyond adjustments to existing practice is often termed "transformational adaptation"-as a grammatical counterpoint to incremental adaptation. It tends to be oriented toward measures that fundamentally reduce exposure to anticipated or observed impacts through a major change in the type, intensity or distribution of a practice (Kates et al., 2012); innovation can be included as long as it is geared toward a stepchange, not simply the incremental evolution of a practice. Studies of these forms of transformation include social analyses, such as work on decision-making processes (for example, Park et al., 2012; Dowd et al., 2014). However, they tend to be structured around notions of environmental drivers that trigger or even force the need for change and hence in essence are a response to an environmental driver, albeit one that is often socially differentiated in its effects (and revealing of structural orders that perpetuate inequality). 
A body of other authors, writing from a critical social science perspective on environmental change, take their visions of transformation in slightly different directions. In parallel with the ideas intended to shape disaster risk reduction, they argue that adaptation should challenge the underlying conditions that generate or perpetuate risk (for example, Pelling, 2011; O’Brien, 2012; Tschakert et al., 2013). Much of this work lies at the boundary of a socio-environmental and a social development agenda, with some authors arguing that systemic transformation of development paradigms is a requirement for effective adaptation. Hence, the critique of "development as usual" by Eriksen et al. (2015) places emphasis not only on the ecological limitations of current development but also on tackling what generates underlying vulnerability and reduces capacity to adapt. Gillard et al. (2016) also caution that over reliance of the field on a systems perspective can downplay the recognition of politics and agency, leading to adaptation approaches for managing change that are unlikely to yield deep-seated transformation because they have not taken sufficient account of the ways in which decisions and options are closed, opened and shaped by actors and relations of power (see also Patterson et al., 2015). This challenges the role of technological innovations and diffusions that might be articulated as transformational, such as alternative crop varieties and water harvesting technologies in drylands (Rickards and Howden, 2012; Rippke et al., 2016) and suggests that technocratic transformations alone do not have the capacity to serve as foundations for societal transformations.

There is an intellectual effort here to shift the adaptation debate away from what are seen as technical/managerial approaches to climate change that deflect attention from the social and political root causes of vulnerability (Wisner et al., 2004; Ribot, 2011) and that arguably perpetuate dominant versions of development (Godfrey-Wood and Naess, 2016). It looks to empower actors to challenge the conditions that generate risk and to promote different forms of development (O'Brien et al., 2014), especially through a broadening and opening-up of processes for decisionmaking, learning and action (Moser and Ekstrom, 2010; Sharpe, 2016). The articulation of the term "transformation" here is therefore inherently normative.

A number of authors take the argument further to challenge what they see as a narrow perspective of transformational adaptation. They look to a wider transformation of development pathways that brings together adaptation, mitigation and sustainable development so that impacts of environmental change are not just managed but avoided (for example, O'Brien et al., 2014; Pelling et al., 2015; Gillard et al., 2016). This envisions a transformation to new development pathways before ecological limits become pressing (Pelling et al., 2015). Drawing on earlier work, O'Brien et al. (2014) propose that three spheres of transformation can be depicted. They view most conventional adaptation activities as instrumental in character and constituting part of a "practical" sphere of behavioural and technical responses, set within two larger spheres of transformation, the "political" sphere of systems and structures and the "personal" sphere of beliefs, values, worldviews and paradigms.

\section{Observing and describing transformation}

Evidently, transformation in adaptation is a conceptually complex field with strongly differing interpretations, and much of the writing on transformation is generalised and not so easy to translate into ideas for concrete action. So how can we look at adaptation as a field of activity and make judgements about transformation? How can we judge if an activity, intervention, policy, strategy, and so on, has transformational character and/or transformative potential?
From the critical social science side especially, scholarship has had difficulty getting beyond generalised (and already quite wellrehearsed) statements about the need for a paradigm shift in approaches to development. O'Brien et al. (2014) look to address this. They provide six recommendations for transforming development paradigms through the political and personal spheres, based on better consideration of local contexts and extending time-frames, participation and empowerment of a range of actors, building in reflexivity, and improving the ways interventions are monitored and evaluated. Though the specific detail with which these actions for transformation are formulated relates to environmental change, in essence these recommendations all reflect established facets of "good" development practice (see, for example, Chambers, 1983; Mikkelson, 1995; Greig et al., 2007; Morchain and Kelsey, 2016). Certainly, there is a long way to go, and arguably most development on the ground still does not follow such elements of good practice, for reasons that are deep-seated and often reside in conservative power structures (Godfrey-Wood and Naess, 2016). But much of what is being called for has long been championed both by development researchers and development practitioners. It is also essentially about process and approach rather than the operational challenge of selecting what to do to generate fundamental change.

Though we would argue that it is critical to take on board the arguments for a deeper form of societal transformation, there are inherent difficulties for research and practice with some of the statements made about the need to change development paradigms. In essence, this form of systemic structural change can only be partial in the short-term: such a transformation is never likely to be a discrete event, but rather a longer term process triggered by a number of different events-some less and some more dramatic (Brown, 2016). Transformation has to work through specific changes, drawing on specific actions that together contribute to the wider shift in society. How else can we observe or achieve it? And, if not, at what point could we observe that a sustainable "system" transformation had taken place?

The cases will be rare in which we can state definitively that an activity has transformational character. Nevertheless, analysis of certain change-related attributes of the action can help in making a judgement of what form and depth of transformation it might entail or entrain. In the introduction to the paper we proposed a set of questions that can be posed to assess how an adaptation action stands in relation to notions of transformation. The responses to these questions correspond to a prototype set of typologies set out in the following subsections of the article, describing:

(A) mechanisms of change

(B) target outcomes in relation to climate risk

(C) the object of change (within or beyond climate change adaptation)

These typologies are essentially about mechanisms and objectives of adaptation action. The categories within them are based on analysis of meanings only-so in essence they are intended to be descriptive, not normative. Nevertheless, the distinction between categories closely relates to differences in the overall ways that the term transformation is conceived in the existing literature and its relationship to development goals. Section 4 provides a reflection on the linkage between the typological distinctions and these themes.

Mechanisms of change. We have argued above that, in practical terms, transformational adaptation has to be seen as constituted 
by specific adaptation (and development) activities. We would also argue that the work of different authors writing in this field points to different mechanisms of change associated with these activities. Drawing together ideas from the full gradation of work on transformation, we suggest that four main types of change mechanism relevant to adaptation have been proposed as potentially constitutive of transformation:

- Innovation = A completely novel activity or application of an activity in a new location;

- Expansion = An application of an existing activity at a much greater scale or much greater intensity;

- Reorganisation =A major change in the governance structures that frame adaptation;

- Reorientation $=\mathrm{A}$ reconfiguration of social values and social relations in adaptation.

These four categories refer to a type of change process. None are necessarily exclusive to transformation (they could plausibly also describe a change that is incremental), but they reflect the main mechanisms of change around which ideas of transformation tend to be discussed. As Table 1 indicates, these categories draw from the contributions of various authors noted above, though none of these authors would adhere exclusively to one category as the sole vehicle of transformation. Innovation and expansion are essentially descriptions of the generation and diffusion of adaptation actions. They are mechanisms of change commonly conveyed in discussions of the transformation potential of technological (and in some cases ecological) forms of adaptation, but could also plausibly apply, for example, to new livelihood practices. Often, though not necessarily always, these two mechanisms of change go hand in hand, and they equate quite closely to O'Brien et al's., 2014 practical sphere of transformation.

The mechanisms labelled here as reorganisation and reorientation refer instead essentially to fundamental changes in how decisions and actions on adaptation are and can be made: changes that might increase adaptive capacity and resilience in a more general sense, though they can still focus around specific sectors. They relate more closely to the ideas of political and personal spheres of transformation (O'Brien et al., 2014). Again the two commonly, though not necessarily, go hand in hand.
Reorganisation refers to a change in the structures that constrain or enable decisions and actions to take place-a change to the organising architecture of governance at various social scales, including both formal and informal institutional arrangements, policies, rules and practices. Such changes, beyond the scope of routine reforms, are increasingly being reported in adaptation governance (see, for example, Anguelovski and Carmin, 2011; Godden et al., 2013). Reorientation is a term designed to capture the idea of change in the values, attitudes, capacities and priorities held by actors at multiple scales, from household to formal government (Colloff et al., 2017). It refers to changes that shape the content of decisions and actions on adaptation, and connects with a growing set of ideas related to social learning as a pathway to transformation (for example, Park et al., 2012; Chung Tiam Fook, 2015).

In theory at least, these four mechanisms of change can apply in combination to the same activity. In practice, one or more of the mechanisms is likely to be attributed more closely to the existence of (or to claims made about) transformation.

Target outcomes in relation to climate risk. A second key question that can be asked of an adaptation activity vis-à-vis transformation is what it seeks to achieve in relation to climate risk. At the heart of this question is concern to understand the depth of change that is being considered, in the light of wellestablished arguments in the literature that highlight the differential social dimensions of risk. Drawing in large part on social critiques within disaster studies (for example, Bankoff et al., 2004; Wisner et al., 2004), writers on adaptation have underlined that vulnerability to climate change impacts is not merely a product of physical exposure to its effects but of variation in social vulnerability: in people's and institution's ability to avoid, resist, cope with, recover from and adapt to the impacts (for example, Adger, 2006; Schipper and Pelling, 2006; Sharpe, 2016). Moreover, the social processes that generate differentiated vulnerability can often be traced to deep-seated underlying factors within society. The discussions on transformation in adaptation reflect differing levels of engagement with the social dimensions of vulnerability. There are clear differences in focus between those writing about transformation in relation to social change that challenges inequity and injustice (for example, Ribot, 2011; Tschakert et al.,

Table 1 | Mechanisms of change

Mechanism

Innovation

A completely novel activity or application of an activity in a new location

Expansion

An application of an existing activity at a much greater scale or much greater intensity

Reorganisation

A major change in governance structures-such as reform of political and administrative architectures, economic policy, and development pathways

Reorientation

A reconfiguration of social values and social relations-such as a major change in attitudes, shifts in social power relations and capacity strengthening of marginal groups
Examples of linkage to existing literature

Novelty and innovation (Folke et al., 2010)

New adaptations; different places or locations (Kates et al., 2012)

New technologies or practices; geographic shifts in the location of activities (Klein et al., 2014)

Practical sphere of transformation (O'Brien et al., 2014)

Enlarged scale or intensity (Kates et al., 2012)

Increase in the magnitude of a management effort (Klein et al., 2014);

Practical sphere of transformation (O'Brien et al., 2014)

Adaptive systemic changes (Walker and Meyers, 2004; Park et al., 2012)

Challenging systems and structures (Denton et al., 2014)

Formation of new structures or systems of governance (Klein et al., 2014);

Fundamental change to functioning of a system, for example, changing institutions (Pelling et al., 2015)

Political sphere of transformation (O'Brien et al., 2014)

Challenging beliefs and behaviours (Denton et al., 2014)

Altering belief systems-knowledge, values and rules (Colloff et al., 2017)

Fundamental change to functioning of a system, for example, changing

individuals' value and behaviour (Pelling et al., 2015)

Learning, reorganization and action (Chung Tiam Fook, 2015)

Personal sphere of transformation (O'Brien et al., 2014) 
2013) and those viewing transformational adaptation to refer to something more narrowly focussing on a systemic response to climate and/or sustainability issues (for example, Kates et al., 2012).

Following this line of reasoning, perhaps we can distinguish differing views of transformational adaptation as having three different target outcomes. In this way, transformational adaptation can be one of the following:

- Instrumental = focuses on addressing climate risk as an environmental problem;

- Progressive $=$ targets reduction of differential social vulnerability to climate risks;

- Radical = tackles underlying causes of social vulnerability to climate risks.

This categorization similarly draws from a comparison of the ways in which transformation is discussed and critiqued in the literature related to environmental change. However, reference to these distinctions tends to be implicit rather than explicitly expressed. The first category refers to activities targeted toward reducing the burden to society of climate risk by reducing overall vulnerability to its effects. Like O'Brien et al. (2014), we employ the label "instrumental" to indicate that this type of activity is strongly oriented to managing the specific environmental problems posed by exposure to climatic change. The types of potentially transformational interventions associated with such a focus are more likely to be technical and technological in form, and the drive to develop them is predominantly shaped by consideration of the physical characteristics of environmental change (Kates et al., 2012; Klein et al., 2014). Consideration of social dimensions focuses principally on how to achieve the political and behavioural conditions to support a change in the direction of intervention. For example, they could include fundamental and often controversial changes in how coastal protection is approached in the face of sea level rise, involving a move away from engineered coastal protection structures toward ecosystem-based adaptation (Jones et al., 2012; Gibbs, 2016).

We use the term "progressive" to denote transformational activities that explicitly recognise the uneven impact that climate risk has on different social groups (according to income, livelihood, sector, gender, ethnicity, disability, age and so on) and that target efforts on reducing the vulnerability of those most likely to be affected. Though discussion of inequities in vulnerability is commonplace in the climate change literature (for example, Adger, 2006; Smit and Wandel, 2006; Eriksen and O'Brien, 2007; Ribot, 2014), inclusion of this category draws less from academic sources on transformation and more from observation of how transformation as a term tends to be used in many interventions. The rationale of the activity is to simultaneously address climate risk as an environmental and a social problem, but the approach to intervention centres on the needs and capacities of high-vulnerability groups and the transformational component is most likely to rest in this social targeting function (Chung Tiam Fook, 2015). This can take the form of activities to reduce exposure of such groups as well as to reduce their sensitivity to impacts and increase their capacities to respond. Potential examples include efforts to target disaster risk reduction to female-headed households identified as particularly vulnerable to subsistence and livelihood losses in hazard-affected areas (for example, Oxfam, 2012) and initiatives to integrate local and scientific forms of knowledge on climate variability and response to deepen access to decision-making resources for poorer farmers (for example, Xu and Grumbine, 2014).

The category "radical" refers to the more deep-seated type of social change envisaged by many who write on transformation in adaptation, in which the target outcome of an activity is to tackle the root causes of social vulnerability and especially differential vulnerability (for example, Pelling, 2011; Ribot, 2014). The aim here is to go beyond action to manage heightened vulnerability and to take action instead that prevents that heightened vulnerability coming into existence. We follow use of the word radical by authors such as Tschakert and St Clair (2013) who underline that the challenge to existing power structures that this type of transformation typically entails should be understood as a radical agenda. Similarly, Gillard et al. (2016: 256) note, response to climate change should not become blueprint but "an opportunity to radically rethink and rebuild social, ecological and economic relations". It is important to convey that such challenges to prevailing structures could be either abrupt and overt, or quite gradual and subtle in operation through a process of empowerment and negotiation.

Radical transformation could include, for example, efforts to redraw what often tend to be entrenched patterns of competition and dominance in the allocation of water and management of river basins (Budds, 2013), or interventions designed to challenge the marginalisation of pastoralism in development policy and strategy in the drylands of East Africa (Catley et al., 2013).

Context is undoubtedly important here too: a routine intervention in one setting could be considered an act of progressive or radical transformation in another. For example, policies to promote women's engagement in resource management decisions may be considered transformational in character in certain regions, while in others they are the cultural norm. Nevertheless, care needs to be taken when making blanket assumptions about contextual distinctions. Rochette (2016), for example, argued that climate change adaptation policies at the federal level in Canada are gender blind even though genderbased analyses and gender mainstreaming policies are in place.

Object of change: transformational or transformative? This third typological dimension interrogates what is the "object" of change, by which we mean what is it that we are seeking to change? Given that we are looking at transformation in relation to adaptation, we can reasonably ask whether the objective is to transform climate change adaptation itself, or to achieve wider societal goals.

As noted, many authors prefer to use the term "transformational adaptation" to connote adaptation activity that has the characteristics of transformation, a linguistic construction that makes grammatical sense when contrasted with incremental adaptation. We would argue that the alternative, often-used term of "transformative adaptation" implies something subtly, yet fundamentally, different.

Some (though not all) dictionary definitions of transformative convey the word as meaning something that has the power to bring about change. Much of the writing on transformation employs the term in this way, with reference to transformative processes, actions, policies, education, learning and so on (see, for example, Tanner and Bahadur, 2013; Walkerden et al., 2013) aimed generally at a broad social transformation or a sustainability transformation.

Using "transformative" as an adjective to "adaptation" therefore implies an adaptation activity that can change other things, as opposed to the adjective "transformational" which implies an adaptation that in itself constitutes a step-change. As examples, a fundamental change in environmental management such as managed realignment in coastal zones could be seen as a transformational adaptation activity, but a livelihood diversification project that reduces women's vulnerability to climate change could be termed a transformative adaptation activity if it also 
triggers a sustained shift in gender relations and empowerment of women (see, for example, CARE International, 2010). Transformative adaptation, in this articulation, refers to adaptation that generates wider transformation.

This leads us to propose two object-defined categories of activity:

- transformational adaptation = adaptation that takes the form of transformation (transformation of adaptation practice)

- transformative adaptation = adaptation that generates transformation (transformation of broader aspects of development through adaptation activity)

This is a subtle difference, and, perhaps unsurprisingly, is once again a distinction that is generally implicit in the literature. Nevertheless, we argue that it may be an important one to highlight, as the two terms are commonly used in an overlapping and confusing way. However, it is also important to underline that they are not necessarily exclusive terms. An adaptation activity can be both transformational in itself, in the approach taken to address climate risk, and transformative of wider social structures as in the example above. Indeed, the deeper forms of transformational adaptation envisaged by O'Brien et al. (2014), Pelling et al. (2015) and Gillard et al. (2016) are generally also articulated as transformative in that they seek also to influence wider development practices.

Transformational adaptation does not necessarily lead to transformative adaptation, and we can suggest the example of forced resettlement to avoid climate hazards as an obviously extreme example of this. While we do posit a reasonable expectation that transformative adaptation is associated with transformational adaptation, we also recognise the possibility that an incremental adaptation could be transformative.

\section{Discussion: linking categories to broad conceptions and critiques}

Having outlined a series of typological dimensions and categories, it is useful to discuss briefly how these relate to the differing conceptions of transformation in adaptation raised in the literature, and particularly what the typological distinctions imply in terms of arguments about equity, sustainability and ultimately depth of transformation.

First, though, it is key to underline that the construction of the typology is as a descriptive-analytical device (Feola, 2015) that tries to encompass and reflect the different ways that the term transformation has and is being used in adaptation debate. Following this reasoning, an adaptation activity that falls into any of the categories above could be considered as having characteristics of transformation. There is also no a priori assumption that one classification is necessarily connected to or leads to another classification: hence the "types", "target outcomes" and the "transformation/transformative" descriptions are in essence describing independent dimensions of an action-each alternative within those can plausibly be linked to any of the others (so, in theory at least, for example, an Innovation could be Instrumental, Progressive or Radical, Transformational and Transformative).

But, of course, that is not the end of it. There are clearly derivable normative discussions to be had around the articulation of categories, on aspects such as depth of change, generality of change, spatial and temporal scale of change and the generation, evolution and permanence of change (Rickards and Howden, 2012; Pelling et al., 2015; Mapfumo et al., 2015). It is important therefore to underline the connections between the typological distinctions and existing critical understandings of the drivers and processes of transformation: to critically assess the options in relation to equity, sustainability, and what is more likely to lead to deeper-seated transformations.

Looking in turn at the broad conceptions of transformation in adaptation outlined earlier in the paper, the set of conceptions drawing from environmental systems and adaptation deficit approaches tend to focus on environmental drivers of change relatively more than social triggers or demands, and to identify forms of transformation that are more closely related to the environmental change problem implied by climate change. There is a tighter emphasis on climate change acting as an amplifier of environmental problems, on the strain of approaching ecological limits, and on environmental crises as enforcing a need for fundamental change (Olsson et al., 2006; Kates et al., 2012; Dow et al., 2013; Colloff et al., 2017) (indeed, such transformations might not always be desired or intended: Walker and Meyers, 2004, for example, refer to forced threshold shifts to "undesirable" ecological states). Hence those viewing transformation from this approach are more likely to focus on environmental-technical solutions achieved through innovation and expansion, with emphasis on instrumental outcomes oriented closely to the climatic hazard, and a primary interest in transformation of adaptation per se (Kates et al., 2012; Klein et al. 2014).

This is a tendency in emphasis being described, not a definitive set of associations. It is important to stress that most of the authors cited above write on themes that cross the margins of these broad interpretations. It also in no way implies that an environmental-limits type perspective on transformation is constrained in ambition, as the challenge implied by addressing underlying ecological limits can be profound indeed. Nevertheless, there are critical aspects of process that merit consideration in relation to evolution, timeframes, scaling and generality of change.

In terms of timescales, for example, Rippke et al. (2016) address the little explored question of when transformations in adaptation need to be triggered and implemented. Looking at climate change adaptation in sub-Saharan agricultural systems, they argue that understanding the needs for transformation in adaptation require long lead-times and this understanding should be developed decades ahead of the need to transform to allow preparatory phases to be put in place for a sustainable shift in practice. A critical perspective on spatial scale is equally important, because transformational adaptation on the level of an economic system, for example, may have consequences that counter adaptive capacity at finer scales of individual livelihoods (Jones et al., 2015).

The underlying challenge here is to acknowledge and think through the existence of trade-offs that may operate through time, space and social difference. Termeer et al. (2016) question the feasibility of transformational changes that are concurrently in-depth, large scale, and rapid because of the inherent trade-offs between them. Even actions that have an evident adaptive value for certain stakeholders can have negative consequences for other social groups or sectors, now or in the future-the existence of social and ecological trade-offs is more likely than not in cases of fundamental change, raising implications for social and environmental justice (Sikor, 2013). Indeed, societal transformation could also proceed in directions that strengthen dominant interests and are in no sense socially progressive or emancipatory (GodfreyWood and Naess, 2016). What all this underlines again is that even if an adaptive response can be described as transformational in type it may not necessarily be positive in outcome-in terms of challenging and changing patterns of vulnerability both equitably and sustainably.

Conceptions of transformation in adaptation drawn from critical social science fields commonly place less or joint emphasis 
on climate change as the driver of transformation, and consequently tend to view the mechanisms and goals of transformation in a broader sense. In such approaches, the drive for transformation is typically articulated as climate change acting as an amplifier of existing social and economic problems, yet, also, potentially providing a vehicle to move beyond common development practice by promoting structural reforms that reduce people's and system's exposure and vulnerability to shocks (Ribot, 2014; Arnall, 2015; Gillard et al., 2016). The factors enabling change are often viewed in relation to social change processes, policy windows of opportunity, emerging leadership and activism, interactions across scales and the redefinition of adaptation as a social-political question (O'Brien, 2012; Tschakert et al., 2013; Pelling et al., 2015; Chung Tiam Fook, 2015; Nagoda, 2015). Hence this approach tends to be associated with discussions around reorganisation and reorientation as mechanisms of change, with an emphasis on progressive and radical outcomes in relation to climate risk, and commonly with transformative goals beyond adaptation practice.

Again, there are important caveats and linkages to consider within this broad association of categories. A first point to underline is that reorganisation, in the way that the term is used in this paper, may need to be accompanied by mechanisms of reorientation if it is to generate socially progressive or, even more so, radical outcomes. This is particularly likely to be the case in situations where technocratic institutional modes of decisionmaking on environmental governance have sufficient inertia to suppress alternative voices on how to manage climate stresses (Tribbia and Moser, 2008; Patterson et al., 2015). As Nalau and Handmer (2015) indicate, if formal structures such as regulatory frameworks change but the actors working within them retain the same mindset and practices then transformation may be illusory. As noted earlier, this also keys in to an emphasis on social learning and participatory processes in many discussions of transformation, implying that transformation is more likely to be found in adaptation approaches that recognise the complexity of social contexts and invite the adaptation agenda to be set by a multitude of knowledges (Eriksen et al., 2015).

In this light, it is crucial that we look critically at the discourse of transformation, considering how different groups and actors are conceptualising and describing the transformation. We can study the power relations of transformational change, asking who is responsible, why is it happening, and how is it influenced, encouraged or impeded (see Moser and Ekstrom, 2010)? Likewise, we could compare the societal outcomes of transformations triggered from the bottom-up with those promoted by politically and economically powerful groups. In perhaps the most telling contribution of research, we can explore examples of progressive and radical transformation being set off by marginalised groups, to better understand what elements are required to enable this transformation. Changing many of the social drivers of vulnerability requires a kind of transformation that challenges the existing structures of power and politics, redefining and opening the political space to marginalised groups (Eriksen et al., 2015). These fundamental shifts, by their very nature, need long time frames to cement systemic and behavioural changes.

It is tempting to further suggest that transformational adaptation solutions to developmental challenges are unlikely to alter existing power structures and their institutions because they alone would not likely challenge systemic deep-rooted inequalities. As such, they are insufficient to promote inclusive, equitable development. Transitioning existing power structures into alternative ones that underpin an equitable system without undertaking radical, transformative change is, therefore, difficult to imagine. In the increasingly occurring contexts of rapid environmental degradation, escalating conflict and economic crises, can instrumental measures be seen as effective long-term responses? Furthermore, can these be more easily overturned and undermined by powerful actors, when the order that elite structures rely on is threatened? Enabling marginalised and less powerful groups of society to adapt beyond the short-term is more likely to happen if founded on transformative elements of adaptation (Brown, 2016).

\section{Conclusion: critical pluralism?}

In this article we explore transformation as a possible attribute of adaptation interventions. The main contribution of the paper is to propose a set of typological distinctions on how the idea of transformation is being applied within the field of climate change adaptation, and to reflect on their implications for research, policy and practice. The underlying aim is to relate conceptions of transformation to practice, and, as the term moves into a mainstream lexicon, to assist researchers and practitioners to understand if and how a transformation might be occurring or be encouraged. Summarizing from the main section of the article, Table 2 proposes a set of questions that could be asked of an adaptation activity. Whether the intention is to analyse an adaptation process or to promote a transformational adaptation, we suggest there is a need to think through how an activity stands, or could stand, against these typological dimensions.

The typological analytical method proposed recognises that not all commentators would accept such a plurality of types, and that contention remains around the question of what significance of change is required for a change to be described as "transformation". Feola (2015: 387) rightly states: “There is a need to resist the fashion of transformation, that is, the temptation of attributing a transformative character to any instance of social change". This point notwithstanding, the term "transformation" is already out there in the public realm, and has, is and will continue to be used in all the categorisations noted in the table above. Transformation as a term in current use has all of these meanings. Indeed, it could be argued that multiple interpretations are an expectation not a definitional problem; perhaps the issue lies instead with critical academics using a non-controversial word when their interpretation of it means something that is inherently controversial and challenging to embedded values (O'Brien et al., 2014; Chung Tiam Fook, 2015; Godfrey-Wood and Naess, 2016)?

While adaptation responses can often be categorised into more than one of the labels we propose, we contend that this granularity can be beneficial when applying transformation thinking to practice (by donors, practitioners and researchers) by providing clarity around the objectives of the adaptation response and around the larger change sought.

Accepting plurality in perspectives of what transformation entails does not remove the need for a critical approach to adaptation. The term transformation generally has a positive connotation, but in almost all cases the "warmth" of this term masks a critical issue that the types of fundamental change that it embodies are likely to have complex and multi-faceted implications, and outcomes that could change with time and changing conditions. As well as consideration of depth of change there are many critical questions to be asked around other dimensions of the change process, including how transformations are triggered and sustained, how they spread through space and how they and their implications evolve through time (Rickards and Howden, 2012; Pelling et al., 2015; Mapfumo et al., 2015). Transformation itself must always be open to critique-as Godfrey-Wood and Naess (2016) note, it may not always be simply positive in its effects. 


\section{Table 2 | Typological distinctions and their implications: interrogating transformation}

Preliminary Question: Is there a fundamental change inherent in an adaptation activity (in relation to practice or capacity)? If yes, proceed with below...

\section{Question}

What type of change

process is occurring or

envisioned?

Typology

Categories

Innovation (completely novel activity or

application of an activity in a new

location)

Expansion (application of an existing

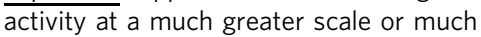

greater intensity)

Reorganization (major change in the

governance structures that frame

adaptation)

Reorientation (reconfiguration of social

values and social relations in adaptation)

How does it relate to the Target outcomes in

drivers of risk? relation to climate risk

Instrumental change (focus on addressing climate risk as an environmental problem) Progressive change (targets reduction of differential social vulnerability to climate risks)

Radical change (tackles underlying causes of vulnerability to climate risks)

Transformational adaptation

(transformation of adaptation practice)

Transformative adaptation

(transformation of broader aspects of development through adaptation activity)
Key linkages

Categories are not necessarily exclusive (they can be combined).

Innovation and expansion tend to relate to technical or behavioural adaptation actions; usually associated with instrumental (and progressive) and transformational categories below.

Reorganization and reorientation are concerned more with changing social structures, including power relations; often associated with progressive/ radical categories and more likely to be transformative.

Categories are intended to be exclusive.

Instrumental is narrow in scope, but addresses the generalised impact of climate change.

Progressive is wider in scope but narrow in terms of its social targeting function; likely to focus on empowerment.

Radical is widest in scope in terms of seeking to tackle and change the underlying social structures and power relations that reproduce vulnerability.

Categories are not exclusive, but the second is more likely to occur in the presence of the first. Adaptation that has a transformative character is generally more likely to promote inclusive and equitable development, and a more sustained reduction of climate vulnerability.
The framework this article proposes hopes to promote structured and critical thinking in the design, implementation and analysis of adaptation and development actions with potential for transformation. This could help reduce the risk of negative impacts on vulnerable or marginalised people, as well as ensure that societal and systemic implications around the breadth of change of a specific transformation are better understood from the outset.

\section{References}

Adger WN (2006) Vulnerability. Global Environmental Change; 16 (3): 268-281.

Anguelovski I and Carmin J (2011) Something borrowed, everything new: Innovation and institutionalization in urban climate governance. Current Opinion in Environmental Sustainability; 3 (3): 169-175.

Arnall A (2015) Resilience as transformative capacity: Exploring the quadripartite cycle of structuration in a Mozambican resettlement programme. Geoforum; 66, 26-26.

Bankoff G, Frerks G and Hilhorst D (2004) Mapping Vulnerability: Disasters, Development and People. Earthscan: London.

Brown K (2016) Resilience, Development and Global Change. Routledge: Abingdon, Oxon and New York.

Budds J (2013) Water, power and the production of neo-liberalism in Chile, 19732005. Environment and Planning D: Society and Space; 31 (2): 301-318.

CARE International. (2010) Adaptation, gender and women's empowerment. CARE International Climate Change Brief, http://www.care.org/sites/default/ files/documents/CC-2010-CARE_Gender_Brief.pdf.

Catley A, Lind J and Scoones I (eds) (2013) Pastoralism and Development in Africa: Dynamic Change at the Margins. Routledge: Abingdon, UK.

Chambers R (1983) Rural Development: Putting the Last First. Longman: Harlow, UK.

Chung Tiam Fook T (2015) Transformational processes for community focused adaptation and social change: A synthesis. Climate and Development; 9 (1): 5-21.

Colloff $\mathrm{M}$ et al (2017) An integrative research framework for enabling transformative adaptation. Environmental Science and Policy; 68, 87-96.
Denton F et al (2014) Climate-resilient pathways: Adaptation, mitigation, and sustainable development. In: Field et al (eds). Climate Change 2014: Impacts, Adaptation, and Vulnerability. Part A: Global and Sectoral Aspects. Contribution of Working Group II to the Fifth Assessment Report of the Intergovernmental Panel on Climate Change. Cambridge University Press: Cambridge, UK, pp 1101-1131.

Dilling L, Daly ME, Travis WR, Wilhelmi OV and Klein RA (2015) The dynamics of vulnerability: Why adapting to climate variability will not always prepare us for climate change. WIREs Climate Change; 6 (4): 413-425.

Dow K, Berkhout F, Preston BL, Klein RJT, Midgley G and Shaw MR (2013) Limits to adaptation. Nature Climate Change; 3 (4): 305-307.

Dowd A, Marshall N, Fleming A, Jakku E, Gaillard E and Howden M (2014) The role of networks in transforming Australian agriculture. Nature Climate Change; 4 (7): 558-563.

Eriksen S and O'Brien K (2007) Vulnerability, poverty and the need for sustainable adaptation measures. Climate Policy; 7 (4): 337-352.

Eriksen S, Håkon Inderberg T, O'Brien K, Sygna L (2015) Introduction: development as usual is not enough. In: Håkon Inderberg T, Eriksen $\mathrm{S}$, O'Brien K and Sygna L (eds). Climate Change Adaptation and Development: Transforming Paradigms and Practices. Routledge: Abingdon, UK, pp 1-18.

Eriksen SH, Nightingale AJ and Eakin H (2015) Reframing adaptation: The political nature of climate change adaptation. Global Environmental Change; 35, 523-533.

Fazey I et al (2017) Transformation in a changing climate: A research agenda. Climate and Development; 1-21.

Feola G (2015) Societal transformation in response to global environmental change: A review of merging concepts. Ambio; 44 (5): 376-390.

Few R, Bendapudi R, Mensah A and Spear D (2016) Transformation in adaptation: learning from ASSAR's Regional Diagnostic Studies. CARIAA-ASSAR Working Paper. International Development Research Centre, Ottawa, Canada and UK Aid, London, www.assaradapt.org.

Folke C, Carpenter S, Walker B, Scheffer M, Chapin T and Rockström J (2010) Resilience thinking: Integrating resilience, adaptability and transformability. Ecology and Society; 15 (4): 20.

Gibbs MT (2016) Why is coastal retreat so hard to implement? Understanding the political risk of coastal adaptation pathways. Ocean \& Coastal Management; 130, $107-114$ 
Gillard R, Gouldson A, Paavola J and van Alstine J (2016) Transformational responses to climate change: Beyond a systems perspective of social change in mitigation and adaptation. WIREs Climate Change; 7 (2): 251-265.

Godden L, Rochford F, Peel J, Caripis L and Carter R (2013) Law, governance and risk: Deconstructing the public-private divide in climate change adaptation. University of New South Wales Law Journal; 36 (1): 224-255.

Godfrey-Wood R and Naess LO (2016) Adapting to climate change: Transforming development? IDS Bulletin; 47 (2): 49-62.

Greig A, Hulme D and Turner M (2007) Challenging Global Inequality: Development Theory and Practice in the 21st Century. Palgrave Macmillan: Houndmills, UK.

IPCC. (2014) Climate change 2014: Impacts, adaptation, and vulnerability. Part A: Global and sectoral aspects. In: Field et al (eds). Contribution of Working Group II to the Fifth Assessment Report of the Intergovernmental Panel on Climate Change. Cambridge University Press: Cambridge.

IPCC. (2014) Annex II: Glossary. In: Pachauri RK and Meyer LA (eds). Climate Change 2014: Synthesis Report. Contribution of Working Groups I, II and III to the Fifth Assessment Report of the Intergovernmental Panel on Climate Change. IPCC: Geneva, Switzerland, pp 117-130.

Jones HP, Hole DG and Zavaleta ES (2012) Harnessing nature to help people adapt to climate change. Nature Climate Change; 2 (7): 504-509.

Jones L, Carabine E and Schipper ELF (2015) (Re)conceptualising maladaptation in policy and practice: towards an evaluative framework. Working Paper, PRISE: London.

Kates RW, Travis WR and Wilbanks TJ (2012) Transformational adaptation when incremental adaptations to climate change are insufficient. Proceedings of the National Academy of Sciences; 109 (19): 7156-7161.

Klein J et al (2014) Adaptation opportunities, constraints, and limits. In: Field CB, Barros VR, Dokken DJ, Mach KJ, White LL (eds). Climate Change 2014: Impacts, Adaptation, and Vulnerability. Contribution of Working Group II to the Fifth Assessment Report of the Intergovernmental Panel on Climate change. Cambridge University Press: Cambridge, UK, pp 899-943.

Mapfumo P et al (2015) Pathways to transformational change in the face of climate impacts: An analytical framework. Climate and Development; 9 (5): 439-451.

Mikkelsen B (1995) Methods for Development Work and Research: A Guide for Practitioners. Sage: New Delhi, India.

Morchain D and Kelsey F (2016) Finding ways together to build resilience - The Vulnerability and Risk Assessment (VRA) methodology: Principles, guide and lessons learned. Oxfam GB: Oxfam.

Moser SC and Ekstrom JA (2010) A framework to diagnose barriers to climate change adaptation. Proceedings of the National Academy of Sciences; 107 (51): 22026-22031.

Nagoda S (2015) New discourses but same old development approaches? Climate change adaptation policies, chronic food insecurity and development interventions in northwestern Nepal. Global Environmental Change; 35, 570-579.

Nalau J and Handmer J (2015) When is transformation a viable policy alternative? Environmental Science and Policy; 54, 349-356.

O'Brien K (2012) Global environmental change II: From adaptation to deliberate transformation. Progress in Human Geography; 36 (5): 667-676.

O'Brien K, Eriksen S, Inderberg TH, Sygna L (2014) Climate change and development: Adaptation through transformation. In: Håkon Inderberg T, Eriksen S, O'Brien K and Sygna L (eds). Climate Change Adaptation and Development: Transforming Paradigms and Practices. Routledge: Abingdon, UK, pp 273-289.

Olsson P, Gunderson LH, Carpenter SR, Ryan P, Lebel L, Folke C and Holling CS (2006) Shooting the rapids: Navigating transitions to adaptive governance of social-ecological systems. Ecology and Society; 11 (1): 18.

Oxfam. (2012) Restoring Livelihoods After Floods: Gender-Sensitive Response and Community-Owned Recovery in Pakistan. Oxfam Programme Insights: Oxford, UK.

Park SE et al (2012) Informing adaptation responses to climate change through theories of transformation. Global Environmental Change; 22 (1): 115-126.

Patterson J et al (2015) Transformations towards sustainability. Emerging approaches, critical reflections, and a research agenda. Earth System Governance Working Paper, No. 34: Lund and Amsterdam.

Pelling M (2011) Adaptation to Climate Change. From Resilience to Transformation. Routledge: Oxford.

Pelling M, O'Brien K and Matyas D (2015) Adaptation and transformation. Climatic Change; 133 (1): 113-127.

Ribot J (2011) Vulnerability before adaptation: Towards transformative climate action. Global Environmental Change; 21 (4): 1160-1162.

Ribot J (2014) Cause and response: Vulnerability and climate in the Anthropocene. Journal of Peasant Studies; 41 (5): 667-705.

Rickards L and Howden SM (2012) Transformational adaptation: Agriculture and climate change. Crop and Pasture Science; 63 (3): 240-250.

Rippke $U$ et al (2016) Timescales of transformational climate change adaptation in sub-Saharan African agriculture. Nature Climate Change; 6 (6): 605-610.
Rochette A (2016) Climate change is a social justice issue: The need for a genderbased analysis of mitigation and adaptation policies in Canada and Quebec. Journal of Environmental Law and Practice; 29, 383-410.

Schipper L and Pelling M (2006) Disaster risk, climate change and international development: Scope for, and challenges to, integration. Disasters; 30 (1): 19-38.

Sharpe J (2016) Understanding and unlocking transformative learning as a method for enabling behaviour change for adaptation and resilience to disaster threats International Journal of Disaster Risk Reduction; 17, 213-219.

Sikor T (2013) The Justices and Injustices of Ecosystem services. Earthscan: Abingdon, UK

Smit B and Wandel J (2006) Adaptation, adaptive capacity and vulnerability. Global Environmental Change; 16 (3): 282-292.

Tanner T and Bahadur AV (2013) Distilling the characteristics of transformational change in a changing climate. Proceedings of Transformation in a Changing Climate, 19-21 June, Oslo, Norway, 33-42.

Termeer CJAM, Dewulf A and Biesbroek GR (2016) Transformational change: Governance interventions for climate change adaptation from a continuous change perspective. Journal of Environmental Planning and Management; 60 (4): $558-576$

Tribbia J and Moser SC (2008) More than information: what coastal managers need to plan for climate change. Environmental Science and Policy; 11 (4): 315-328.

Tschakert P and St Clair AL (2013) Conditions for Transformative Change: The Role of Responsibility, Care, and Place Making in Climate Change Research. Proceedings of Transformation in a Changing Climate, 19-21 June, Oslo, Norway, 267-275.

Tschakert P, van Oort B St, Clair AL and LaMadrid A (2013) Inequality and transformation analyses: A complementary lens for addressing vulnerability to climate change. Climate and Development; 5 (2): 340-350.

Walker B and Meyers JA (2004) Thresholds in ecological and social-ecological systems: A developing database. Ecology and Society; 9 (2): 3.

Walkerden G, Ryan P, Griffith R and Robinson S (2013) Exploring transformation for resilient Australian landscapes and communities. Proceedings of Transformation in a Changing Climate, 19-21 June, Oslo, Norway, 169-177.

Wisner B, Blaikie P, Cannon T and Davis I (2004) At Risk: Second Edition, Natural Hazards, People's Vulnerability and Disasters. Routledge: London.

$\mathrm{Xu} \mathrm{J}$ and Grumbine RE (2014) Integrating local hybrid knowledge and state support for climate change adaptation in the Asian Highlands. Climatic Change; 124 (1): 93-104.

\section{Data availability}

Data sharing is not applicable to this article as no datasets were generated or analysed in its production.

\section{Acknowledgements}

This work was carried out under the Adaptation at Scale in Semi-Arid Regions project (ASSAR). ASSAR is one of four research programmes funded under the Collaborative Adaptation Research Initiative in Africa and Asia (CARIAA), with financial suppor from the UK Government's Department for International Development (DfID) and the International Development Research Centre (IDRC), Canada. The views expressed in this work are those of the creators and do not necessarily represent those of DfID and IDRC or its Board of Governors.

\section{Additional information}

Competing interests: The authors declare that there are no competing financial interests.

Reprints and permission information is available at http://www.palgrave-journals.com/ pal/authors/rights_and_permissions.html

How to cite this article: Few R, Morchain D, Spear D, Mensah A and Bendapudi R (2017) Transformation, adaptation and development: relating concepts to practice. Palgrave Communications. 3:17092 doi: 10.1057/palcomms.2017.92.

Publisher's note: Springer Nature remains neutral with regard to jurisdictional claims in published maps and institutional affiliations.

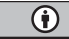

This work is licensed under a Creative Commons Attribution 4.0 International License. The images or other third party material in this article are included in the article's Creative Commons license, unless indicated otherwise in the credit line; if the material is not included under the Creative Commons license, users will need to obtain permission from the license holder to reproduce the material. To view a copy of this license, visit http://creativecommons.org/licenses/by/4.0/

C The Author(s) 2017 